\title{
Development and Validation of a Tool on Social Intelligence
}

\author{
Karrthik Ramanathan ${ }^{1 *}$
}

\section{ABSTRACT}

The aim of the study was to develop and validate a tool to measure the social intelligence quotient of employees at the workplace, especially during the time of recruitment. The tool was developed based on the five-part model of social intelligence developed by Karl Albrecht (2005). The sample for the study was selected using the snowball sampling technique and comprised of 222 people both males and females belonging to the age group 18-25 years and was of Indian origin. The steps of the study included the generation of the initial pool of items, expert validation, item analysis, followed by tests for reliability and validity. The data was collected online through google forms. Item total correlation, descriptive statistics, and structural equation modelling were used to analyse the data. The reliability of the scale established using Cronbach's alpha (internal consistency) was found to be 0.87 (high). The scale was correlated with Tromso Social Intelligence Scale (TSIS) to establish criterion validity and was found to be 0.164 ( $<<.01)$. The intra-correlation among the dimensions of the tool was found to be moderate, ranging between $0.42-0.57$.

\section{Keywords: Social Intelligence, Psychometric Tool, SPACE model, Likert scale}

7 The behavior of an individual can be best understood under the specific social context because a social climate triggers the behaviour as claimed by Lewin. He proposed that behaviour is the function of the interaction between a person and the environment $\{B$ $=f(\mathrm{P} \times \mathrm{E})\}$. Further, the need hierarchy theory proposed by Maslow lays emphasis on the need for love and belongingness followed by the need for self-esteem, indicating the underlying psychological phenomenon i.e., social intelligence.

Social intelligence from initially being viewed as a personality trait (Thorndike, 1920; Moss \& Hunt, 1927; Vernon, 1933) has evolved a lot. It was seen as one's social judging ability (O'Sullivan, Guilford, \& DeMille, 1965), as one's ability to interpret social cues and regulate accordingly (Cantor \& Kihlstrom, 1987), as a problem-solving skill, and as a knowledge of social rules (Barnes \& Sternberg, 1989), and quite recently as a set of interpersonal competencies that can enable efficient human behavior (Bar-On, 2005).

Social intelligence as a concept has undergone a lot of changes in the way it's been defined since the term was first coined by Thorndike (1920) and defined as "one's ability to understand and manage other people and to engage in adaptive social interactions." Later

\footnotetext{
${ }^{1}$ Master of Science, Department of Psychology, Christ (Deemed to be) University, Bangalore, India. *Corresponding Author

Received: July 23, 2021; Revision Received: September 03, 2021; Accepted: September 15, 2021

(C) 2021, Ramanathan K.; licensee IJIP. This is an Open Access Research distributed under the terms of the Creative Commons Attribution License (www.creativecommons.org/licenses/by/2.0), which permits unrestricted use, distribution, and reproduction in any Medium, provided the original work is properly cited.
} 
on, in the year 1926, Guilford \& Burke corresponded the very term social intelligence with sociability as measured by different variables such as the number of self-reported friends, social events attended, and the amount of written communication.

According to some other researchers, social intelligence is one's capability to explain a given social situation with respect to the behavior inputs of others present, rather than concerning his/her feelings about the others (Chapin, 1942; Wedick, 1947). In the words of Wechsler (1958), it is a capacity to deal with human beings. Whereas, Weinstein (1969) defined it as one's capacity to complete interpersonal tasks.

Furthermore, Gardner (1983) in his model of multiple intelligence instead of social intelligence, mentioned personal intelligence which comprises interpersonal and intrapersonal intelligence. Researchers have defined interpersonal intelligence as one's ability to comprehend and work in tandem with others and comprise of one's ability to differentiate and respond aptly in line with the attitudes, temperaments, drives, and requirements of others (Cherniss, Extein, Goleman, \& Weissberg, 2006; Goleman, 1995).

Since society undergoes many changes from generation to generation, the way social intelligence is defined has also gone through multiple changes. Hence in the year 2003, Albrecht defined it as one's ability to interact well with others and thereby achieving their full cooperation. It focuses on interpersonal skills and the behavior people display toward each other.

\section{THEORETICAL FRAMEWORK}

\section{Karl Albrecht's Five-Part Model of Social Intelligence (2005)}

Albrecht in the year 2005 proposed a model to understand the phenomenon of social intelligence in the modern society. According to his model of social intelligence, there are five major components through which social intelligence of an individual can be understood. Those five components are situational awareness, presence, authenticity, clarity, and empathy.

\section{Figure 1 Karl Albrecht's Five-Part Model of Social Intelligence}

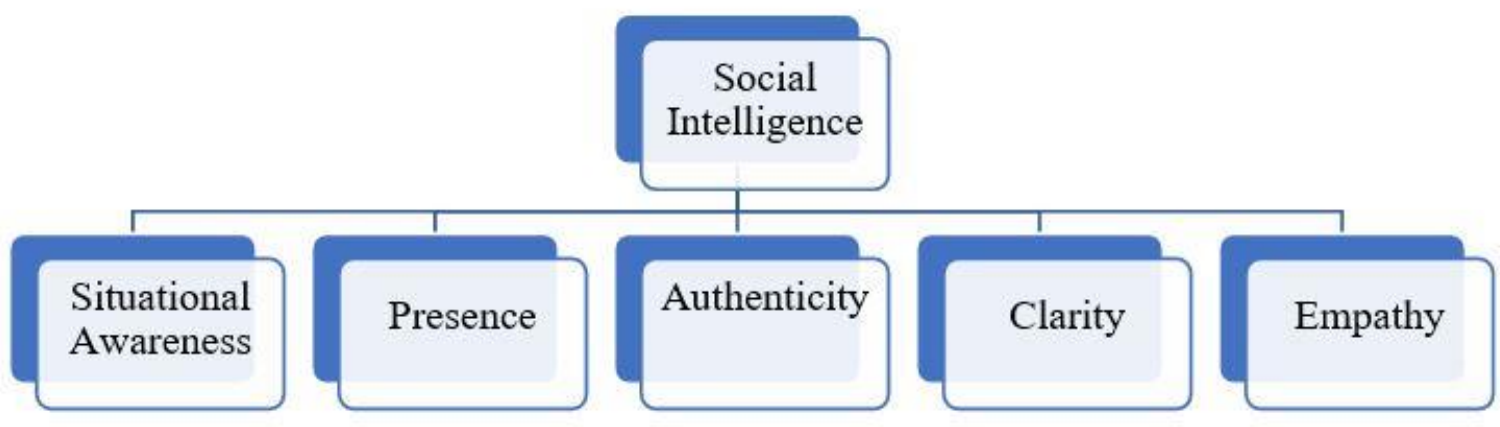

Situational Awareness. The capacity to observe and understand the context of a situation one may find oneself in, and to understand the role played by the situation in shaping people's behavior who are a part of it.

Presence. The impression conveyed by one to others with regards to their behaviour. People tend to draw conclusions about one's character, capability, and one's sense of his/her self on the basis of the behaviors they observe. 
Authenticity. How far others perceive one as acting with honesty and ethical intentions. The extent to which others feel one's behavior is in line with his/her personal values.

Clarity. The capacity to express one's thoughts effectively with clarity and impact. It embodies a wide array of conversational skills such as listening, providing feedback, paraphrasing, semantic flexibility, skillful utilization of language, and the competency to explain things simply and precisely.

Empathy. The skill of forming social relationships with people - refers to one's ability to get people to meet him/her on a personal level of respect and readiness to cooperate. Empathy here goes beyond the traditional idea of having a feeling toward another person, it deals with creating a mutual feeling between oneself and another person.

The researcher opted to base his scale on Karl Albrecht's five-part model of social intelligence because of its comprehensiveness and more relevant view of the construct being measured i.e., social intelligence than other theories given the range of dimensions it caters to. Secondly, the theory was also developed relatively recently in the year 2005, which he feels makes it more applicable in the present context than the ones developed decades back.

Lastly, literature evidence also supports the relevance of the dimensions mentioned in the theory when measuring one's social intelligence and also point out the lack of an objective tool to measure the same (Weis, 2008).

\section{Existing Scales Measuring Social Intelligence}

Emotional Quotient - Inventory (Bar-On, 1997) consists of 133 items intended to measure an individual's emotional and social intelligence. It assesses 5 major areas of an individual which are namely intrapersonal, interpersonal, stress management, adaptability, and general mood. Cronbach alpha (internal consistency) and test-retest reliability were found to be 0.97 and 0.72 respectively. Convergent validity was established by correlating EQ-i and other ESI instruments and was found to be $36 \%$ whereas the divergent validity was established by correlating EQ-i and IQ scales, EQ-i, and personality scales and were found to be $4 \%$ and $15 \%$ respectively.

Tromso social intelligence scale was developed by Silvera et al. (2001) consisting of 21 items measuring three different components of social intelligence, which are namely social information processing (SIP), social skill (SS), and social awareness (SA). Cronbach alpha (internal consistency) was found to be $0.81,0.86$, and 0.91 respectively for SIP, SS, and SA. The concurrent validity was established by correlating with Marlowe Crowne Social Desirability Scale (MCSD) and was found to be 0.22 .

The Emotional and Social Competence Inventory (Boyatzis \& Goleman, 2006) comprises 68 items aimed at measuring one's emotional competencies and positive social behaviors. It evaluates four aspects related to an individual's behavior which are namely self-awareness, social awareness, self-management, and relationship management. Cronbach alpha (internal consistency) was found to be $0.83,0.85,0.81$, and 0.83 respectively for SA, SM, SoA, and RM. The scale's convergent and discriminant validity was found to be ranging from $0.80-$ 0.90 .

The social intelligence scale (Habib, Saleem \& Mahmood, 2013) was aimed at developing a native, ecologically valid, and reliable tool for assessing social intelligence in Pakistan. The scale consists of 98 items measuring social manipulation, social facilitation, social empathy, 
extroversion, and social adaptability. The test-retest reliability, split-half reliability, and Cronbach alpha (internal consistency) values of the scale were found to be $0.88,0.78$, and 0.78 respectively. The construct validity (convergent validity) for the scale was established by correlating it with Bar-On EQ-I.

The Manipulation, Empathy and Social Irritability (MESI) scale (Frankovský \& Birknerová, 2014) consist of 21 items assessing three major aspects of an individual's behavior including manipulation, empathy, and social irritability. Cronbach alpha (internal consistency) was found to be $0.85,0.78,0.71$ respectively for M, E, and SI. The validity of the scale was established by correlating it with Tromso Social Intelligence Scale (TSIS) and was found to be 0.34 .

\section{Significance of SI}

Weis (2008) conducted an empirical investigation to substantiate the construct both theoretical and methodological and to develop a test battery of social intelligence. In the first part of the study, 127 students of the Otto-von-Guericke-University Magdeburg in Germany were administered tasks testing their social intelligence, social understanding, social memory, social perception. BIS test, Neo-FFI were used as validation instruments. A list of tasks both related and unrelated to the research questions were also administered. In the second part of the study, 182 students of the Otto-von-Guericke-University Magdeburg belonging to the age group 23-40 in Germany were administered the list of tasks mentioned in study 1 with some modifications and extensions. The findings of the study revealed a hierarchical model of social intelligence supported by data. Ratings-based scales seem to have been found to work better than the other two item formats. The social intelligence structural model proved structural independence from academic intelligence.

Ebrahimpoor, Zahed, and Elyasi (2013) conducted a quantitative study to examine the relationships among different dimensions of social intelligence as measured by TSIS on organizational performance. 164 managers and experts belonging to Ardabil regional water company were administered the TSIS questionnaire and a balanced scorecard to measure social intelligence and organizational performance respectively. The presence of a positive and significant relationship between social intelligence and organizational performance was found. Different dimensions of social intelligence such as social skills, social information processing, social awareness, and social desirability were found to have a significant positive proportional relationship individually with organizational performance.

Rostamian and Sadrabadi (2016) conducted a study to determine the relationship between social intelligence and service presentation quality in Esfahan city Melat bank (selected branches). The sample consisted of 269 staff and 800 customers who were administered TSIS and Servqual standard questionnaires to measure social intelligence and service presentation quality respectively. The findings of the study clearly establish the presence of a positive and proportional relationship between social intelligence and social services quality. Amongst the three factors of social intelligence measured by TSIS, the social skill was found to have the greatest effect on service presentation.

\section{Relationship between SI, EI, and CQ}

Crowne (2009) carried out an empirical study to establish the presence of a relationship between Emotional Intelligence (EI) and Cultural Quotient (CQ), and to showcase how each was discrete, but associated constructs, as well as subsets of Social Intelligence (SI). The findings of the study support the idea that EI and CQ are subsets of SI, it validates the 
distinctions between EI and CQ with tangible evidence and further deliberates upon the similarities between CQ and EI. It also establishes the need for organizations to take into account all three factors when trying to impart leadership skills to the employees.

\section{The Validity of Scales in the Indian Context}

Goswami (2019) carried an empirical study to investigate the factor structure of the Tromso Social Intelligence Scale (TSIS) in the Indian context and also to explore the difference between the factor structures of the TSIS in India from the one in the west. The findings of the study reveal that the factor structure of TSIS in the Indian context is different from the original scale developed in Norway. The results divulge a four-factor structure in the Indian context in contrast to the three-factor structure of the original scale.

\section{Relationship between SI and Academic Achievement (IQ)}

Baggiyam and Pankajam (2017) carried out an investigation to find out the relationship between social intelligence and academic achievement among schoolchildren. The findings indicate a mild positive correlation between social intelligence and academic achievement. It further pointed out that most of the sampled population possessed a moderate level of social intelligence with very few belongings to both the extremes (high and low).

\section{Research Gap}

Analysis of literature points out that despite the surge in the number of scales constructed and validated to access general intelligence for a century now there have been very limited attempts made in constructing and validating tools to measure social intelligence (Taylor, 1990). Also, most of the scales used for measuring social intelligence at present are sparsely based or supported by any theoretical model (Weis, 2008). It further points out the lack of cultural fitness of most of the existing scales used for measuring social intelligence by organizations in our country as they were developed in western countries based on their cultural and social norms.

For example, the most commonly used scale, the Tromso intelligence scale was found to be inappropriate in our cultural context (Goswami, 2019). Also, only in very few cases efforts have been made to explore the cross-cultural validity of these scales. Also, most of the existing scales were found to be focusing excessively on measuring one's emotional intelligence, which is only a subset of social intelligence and would not provide a complete picture of one's social intelligence (Crowne, 2009).

Almost all of the existing scales analyzed barring Social Intelligence Profile (SIP) none have focused on the dimensions of social intelligence emphasized by Karl Albrecht in his theory of social intelligence barring the only exception of situational awareness. But studies done in recent times have increasingly supported the importance of taking into account these dimensions when assessing one's social intelligence which at present is being measured subjectively due to the lack of an objective measure. This tool is aimed at bridging the gaps mentioned above.

\section{Rationale}

With the advent of globalization and technological advancements, the world has become a global village and organizations are no exception to it. With diversity at the workplace being at a record high juxtaposed with decreasing tolerance level among people it becomes highly imperative to hire people who would fit in an organization, get along well with people, coordinate and work as a team. 
Employees who know how to behave in a social situation, who are good at understanding both their own selves as well as others, possess empathy, good communication, and social skills become an asset to the organization to which he/she belongs. This scale would help employers pick the employees who would be the best fit for their organization's sustenance as well as progress.

\section{MATERIALS AND METHODS}

\section{Aim}

The aim of the study was to develop and validate a tool to measure the social intelligence quotient of employees at the workplace, especially during the time of recruitment using Karl Albrecht's SPACE model of social intelligence.

\section{Objectives}

- To construct a psychometric tool to measure a person's level of social intelligence.

- To ensure that the tool was of optimal length, easy to understand, and respond to, for the participants.

- To develop a culturally appropriate tool.

- To construct a tool that can be instrumental in helping employers recruit the right employees.

- To make sure that the tool was reliable and valid.

\section{Design}

A correlational design was utilized to develop the tool by the process of construct validity because an existing theory on social intelligence (Albrecht, 2005) was identified which has five factors, namely - situational awareness, presence, authenticity, clarity, and empathy. Under correlational design, Structural Equation Modelling (SEM) was followed which is a useful statistical procedure for tool development as it estimates the multiple and interrelated dependence in a single analysis (Statistics Solutions, 2020).

\section{Sample}

The sample comprised 222 participants, including both males and females between the age range of 18-25 years, and was of Indian origin.

\section{Sampling Procedure}

The sample for the study was selected using a snowball sampling technique, which is a type of non-probability sampling. The final sample was drawn on the basis of inclusion and exclusion criteria, which is as follows:

\section{Inclusion/Exclusion Criteria Inclusion Criteria}

Individuals belonging to the age group of 18-25 years, who were of Indian origin and were literates. Individuals across different educational streams, occupations were included in the sample. People were not excluded on the basis of their marital status, family type, state, and locale.

\section{Exclusion Criteria}

Individuals belonging to the age group of 18-25 years, who either stayed in India but were not of Indian origin, or those who were not literates, or both. 


\section{Demographics}

Figure 2 (A) Age Distribution of the Participants

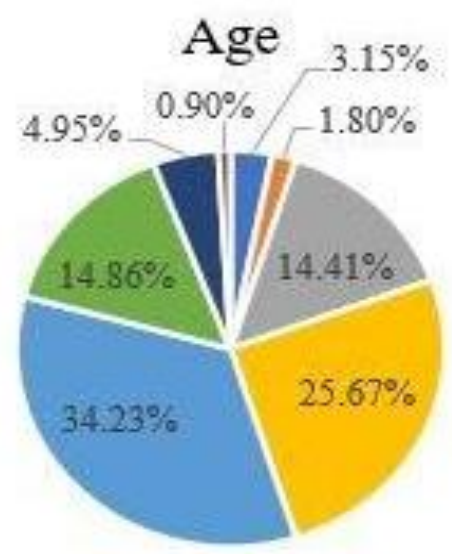

$-18=19=20=21=22=23 \cdot 24 \cdot 25$

Figure 2 (B) Gender Distribution of the Participants

Gender

222 responses

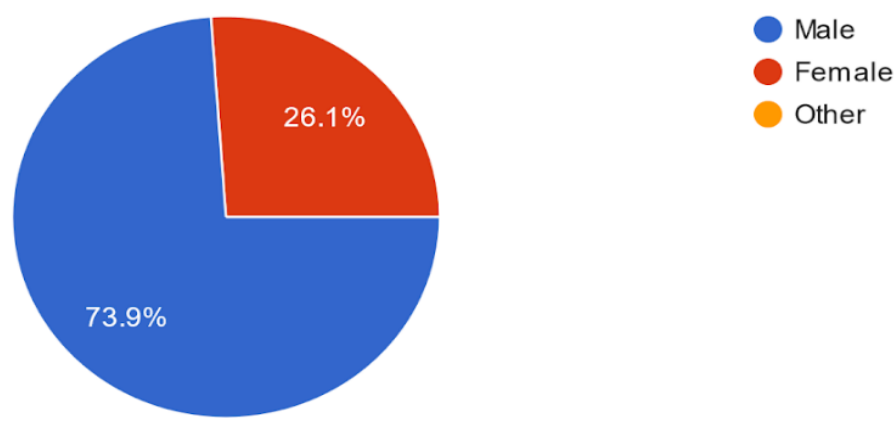

Figure 2 (C) Educational Qualification Breakdown of the Participants

\section{Educational Qualification}

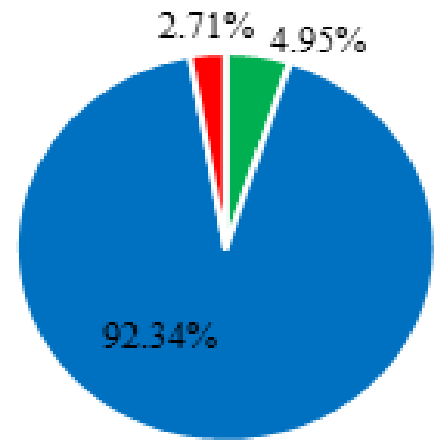

-X/XII - UG/PG -Diploma/I.T.I

(c) The International Journal of Indian Psychology, ISSN 2348-5396 (e)| ISSN: 2349-3429 (p) | 1546 
Figure 2 (D) Educational Stream Distribution of the Participants

Stream

222 responses

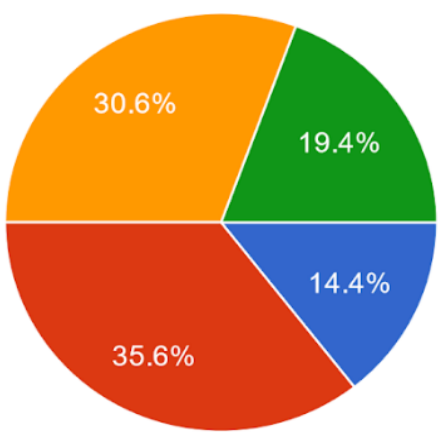

Family Type

222 responses

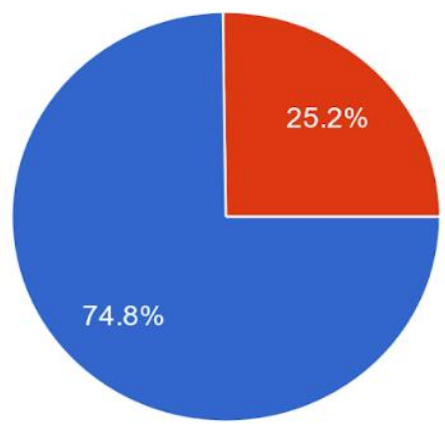

Figure 2 (F) Locale Distribution of the Participants

\section{Locale}

222 responses

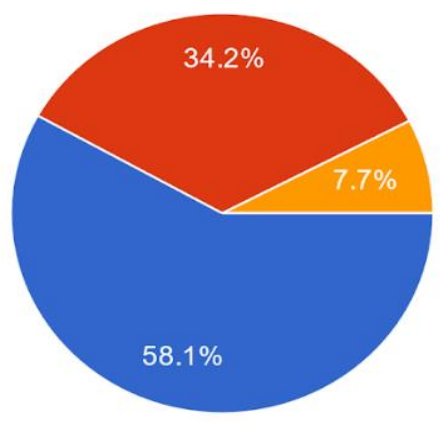

\section{Tools Used}

The following tools were used in the present investigation:

(c) The International Journal of Indian Psychology, ISSN 2348-5396 (e)| ISSN: 2349-3429 (p) | 1547 
A. Self-developed questionnaire on social intelligence [SI; R Karrthik, (2020)]:

It is a self-report measure consisting of 34 items measuring five different components of social intelligence, which are namely situational awareness, presence, authenticity, clarity, and empathy. It is developed based on Karl Albrecht's SPACE model of social intelligence (Albrecht, 2005). The situational awareness sub-scale consists of 11 items, whereas presence, authenticity, clarity, and empathy sub-scales consist of 4,4,7, and 8 items respectively. A 5point Likert scale was used to record responses from the participants.

\section{B. Tromso Social Intelligence Scale [TSIS; Silvera et al, (2001)]:}

Tromso social intelligence scale was developed by Silvera et al. (2001) as an effective way to measure one's social intelligence level. It is a self-report measure consisting of 21 items measuring three different components of social intelligence, which are namely social information processing (SIP), social skill (SS), and social awareness (SA). Each subscale consists of 7 items and a 5-point Likert scale was used to record responses from the participants.

The minimum and maximum scores obtainable in the subscales are 7 and 35 respectively. Cronbach alpha was found to be $0.81,0.86$, and 0.79 respectively for SIP, SS, and SA. The scores obtained in the scale were correlated to the scores obtained in Marlowe Crowne Social Desirability Scale (MSCD) to establish convergent validity and it was found to be 0.22 .

\section{Eysenck's Personality Inventory (Lie Score) [EPI; Hans and Sybil Eysenck, (1964)]:}

The Eysenck Personality Inventory (EPI) is a self-report measure designed to measure two personality traits, which are extraversion and neuroticism respectively. The scale was developed by Hans and Sybil Eysenck in the year 1964. The scale consists of 57 yes/no items and provides total scores for extraversion and neuroticism as well as a validity score (i.e., Lie Scale). There are 24 items measuring extraversion and neuroticism respectively and 9 items tapping into one's social desirability (lie score). Cronbach alpha was found to be $0.89,0.92$, and 0.78 respectively for Extraversion, Neuroticism, and Lie scores.

\section{Operational Definition}

Social intelligence: Social intelligence is operationally defined as the score obtained by a person in the self-developed social intelligence questionnaire. People who are scoring high on this scale are said to be high in the five dimensions of social intelligence discussed in Karl Albrecht's five-part model of social intelligence which are namely situational awareness, presence, authenticity, clarity, and empathy.

\section{Procedure}

\section{Generation of Initial Pool of Items and Expert Validation}

The researcher initially generated a pool of items (72 questions) based on the theoretical model of social intelligence developed by Karl Albrecht (2005). Each item designated for the initial pool of items mirrored applicability towards social intelligence within the ambit of the selected theoretical model. To specify the extent to which each item described them appropriately, the respondents were asked to make use of a 5-point Likert scale, where $1=$ Strongly disagree, 2 $=$ Disagree, $3=$ Neutral, $4=$ Agree and $5=$ Strongly agree. All five different dimensions of the model were represented by several items.

Post item generation, they were given to three experts belonging to the fields of sociology and social psychology for expert validation. Based on the feedback received from the experts, certain modifications were made with respect to the ways in which the items were worded, 
and few items which were found to be redundant and not very appropriate to the construct were also be removed and at the end out of the total 72 items initially generated 34 were retained in the scale.

\section{Study}

Following expert validation, the questionnaire was administered to a sample of 222 individuals both males and females belonging to the age group 18-30 years and are of Indian origin alongside with Tromso social intelligence questionnaire and Eysenck's Personality Inventory (Only questions tapping on social desirability). Responses obtained were filtered based on the score obtained by participants in the Eysenck's Personality Inventory i.e., participants who had a lie score of 5 or more were eliminated from the study. The data collected through the self-developed questionnaire was used to carry out item analysis to understand the quality of individual items which in turn was helpful in determining the extent to which each item measured the dimension of the construct it is supposed to measure. It was further utilized to carry out descriptive statistics, structural equational modelling, tests of reliability and validity.

\section{Data Collection}

The survey method was used to collect the responses of the participants. Data was collected through Google forms. Online data collection methodology was used to collect data due to the pandemic situation where it was hard to meet people in person. It was also preferred because of its ease to collect, store, and analyze the data collected. It was also said to improve the efficiency of the data collected and minimize the chances of any data losses.

\section{Steps}

- Literature review to identify and understand the existing theories of social intelligence.

- Karl Albrecht's five-part model of social intelligence was chosen to develop the tool. Due to lack of tools at present and also to suit the diversified Indian culture.

- Based on the chosen theory items were generated. A total of 72 items were generated tapping into 5 different dimensions of social intelligence as described in the theory.

- The initial pool of items generated was sent to three experts belonging to the fields of sociology, and psychology.

- Based on the feedback received from the experts few items were modified and few items that were considered to be redundant and not so relevant were removed. A total of 34 items were retained post expert validation.

- Following expert validation, the tool was sent to people who fulfilled the inclusion criteria for data collection. The sample consisted of a total of 222 individuals, 164 males, and 58 females.

- Individuals who had a lie score equal to or greater than 5 in Eysenck's Personality Inventory were not considered for the data analysis. A total of 182 participants, 130 males, and 52 females were retained for the data analysis.

- Data of the retained participants were subjected to statistical analysis, Structural equation modelling (SEM) in this case.

\section{Common Instructions}

The study consists of 4 different sections, the first one consists of questions relating to your demographic details whereas the remaining sections have questions relating to the study. Please read the instructions given at the beginning of every section thoroughly before answering the questions. There are no right or wrong answers to any of these questions kindly 
select the option which you feel is the most appropriate one for you. Please answer the questions with utmost honesty. Do not omit/skip any questions.

\section{Statistical Analyses}

Item total correlation and descriptive statistics such as mean, standard deviation were utilized to carry out item analysis. Item analysis is used to evaluate the quality of individual test items. Structural equation modelling was used to test the hypothesized patterns of relationship between the factors. Cronbach's alpha (internal consistency) was used to measure the reliability of the scale developed. The validity of the scale was established by correlating the scores obtained by the participants in the scale with that of the score obtained by them in the Tromo Social Intelligence Scale (criterion validity).

\section{RESULTS AND DISCUSSION}

The aim of this study was to confirm the factor structure derived based on Karl Albrecht's Five-Part Model of Social Intelligence (SPACE). Confirmatory factor analysis (CFA) through structural equation modeling (SEM) in AMOS 23 was used to attain this objective. The results are presented in the following section.

\section{Confirmatory Factor Analysis}

There was good internal consistency between the items $(\alpha=0.843)$ in the sample. Factor wise internal consistency assessment indicated Situational Awareness had an $\alpha$ of 0.694, Presence had an $\alpha$ of 0.569 , Authenticity had an $\alpha$ of 0.478 , Clarity had an $\alpha$ of 0.654 , and Empathy had an $\alpha$ of 0.427 .

Based on the theoretical framework used to develop the statements it was hypothesized that the five factors will be correlated with the construct of social intelligence as depicted below.

\section{Figure 3 Hypothesized Model}

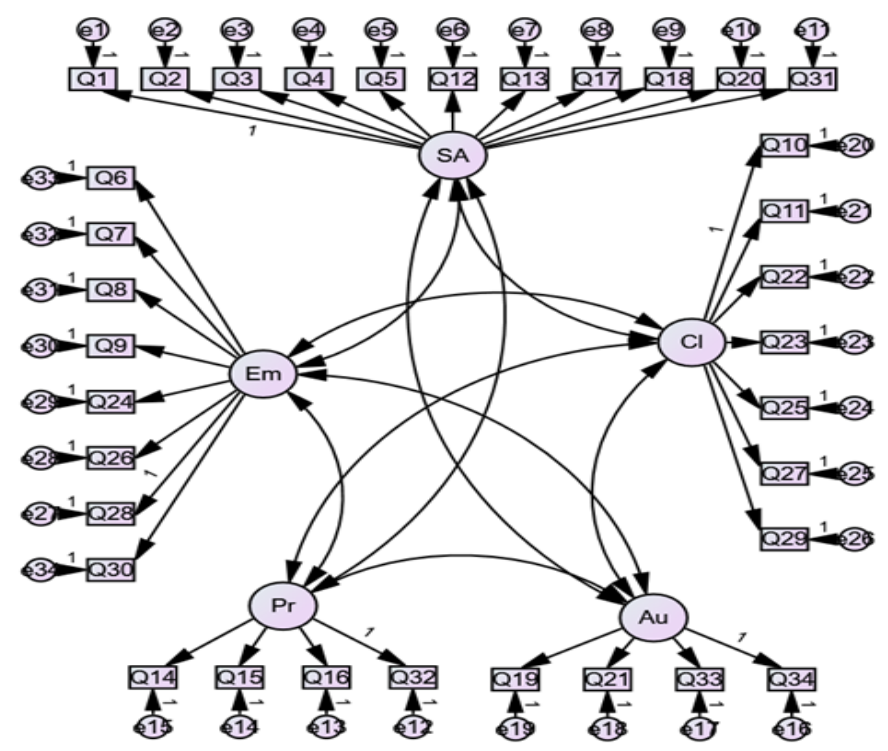

A confirmatory factor analysis was estimated to test the presence of a five-correlated factor construct of social intelligence (Figure 4). 
Figure 4 Five-correlated factor model of Social Intelligence

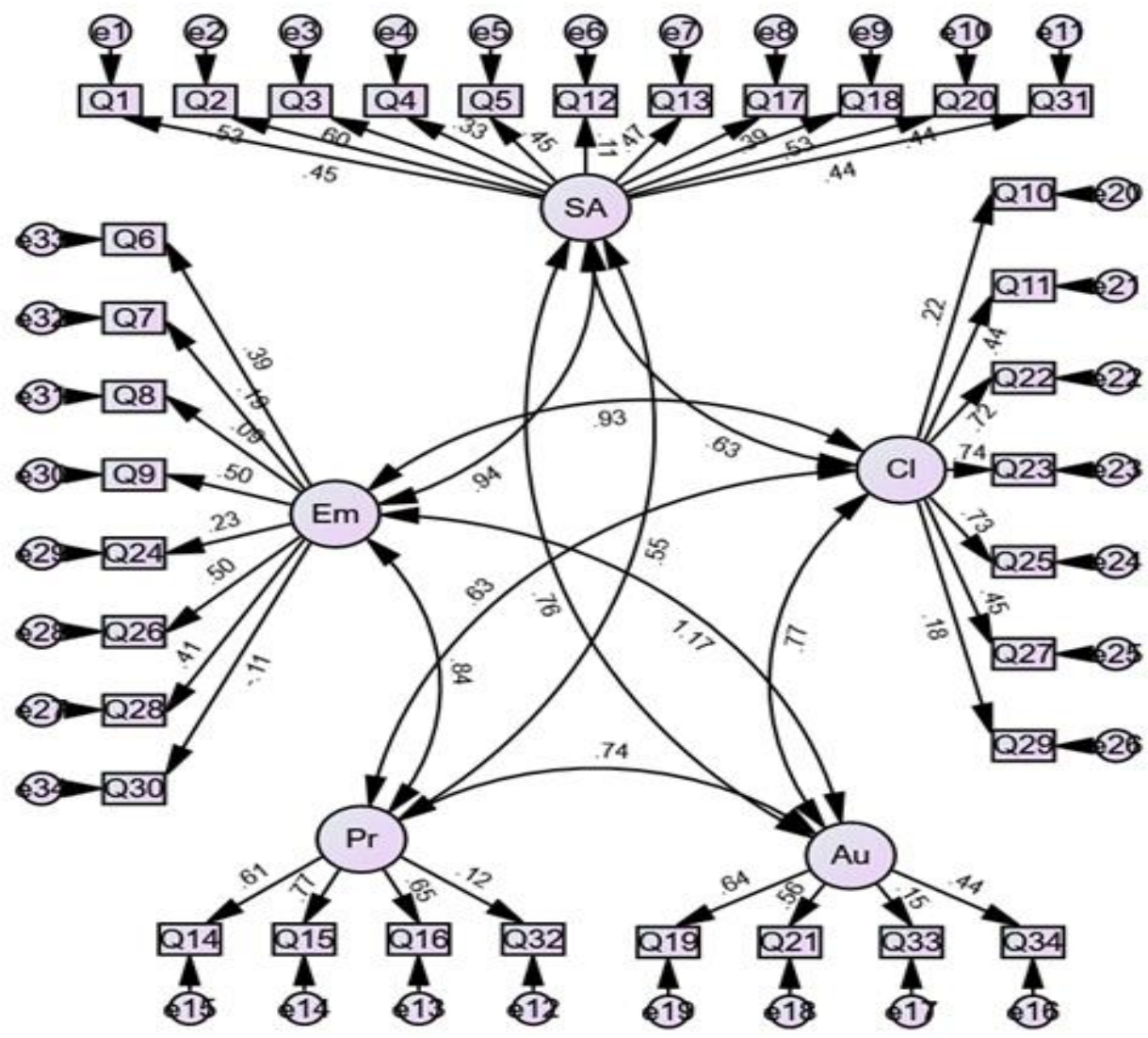

Table 1 (a) Standardized and Unstandardized Factor Loadings of the Model and between Factor Covariance on Situational Awareness

\begin{tabular}{lllll}
\hline Item \# & $\mathbf{B}$ & SE B & $\boldsymbol{\beta}$ & \\
\hline @1 & 1 & & 0.450 & Retained \\
$@ 2$ & 1.117 & 0.241 & 0.532 & Retained \\
$@ 3$ & 1.266 & 0.258 & 0.601 & Retained \\
$@ 5$ & 0.957 & 0.226 & 0.451 & Retained \\
@13 & 1.013 & 0.233 & 0.472 & Retained \\
$@ 18$ & 1.277 & 0.275 & 0.534 & Retained \\
@ 20 & 1.028 & 0.245 & 0.445 & Retained \\
$@ 31$ & 0.945 & 0.228 & 0.435 & Retained \\
\hline
\end{tabular}


Development and Validation of a Tool on Social Intelligence

Table 1 (b) Standardized and Unstandardized Factor Loadings of the Model and between Factor Covariance on Presence

\begin{tabular}{lllll}
\hline Item \# & B & SE B & $\boldsymbol{\beta}$ & \\
\hline @ 14 & 4.9 & 3.513 & 0.614 & Retained \\
@ 15 & 5.422 & 3.867 & 0.773 & Retained \\
@ 16 & 4.082 & 2.922 & 0.649 & Retained \\
\hline
\end{tabular}

Table 1 (c) Standardized and Unstandardized Factor Loadings of the Model and between Factor Covariance on Authenticity

\begin{tabular}{lllll}
\hline Item \# & B & SE B & $\boldsymbol{\beta}$ & \\
\hline @ 19 & 1.609 & 0.31 & 0.645 & Retained \\
@21 & 1.274 & 0.262 & 0.557 & Retained \\
$@ 34$ & 1 & & 0.436 & Retained \\
\hline
\end{tabular}

Table 1 (d) Standardized and Unstandardized Factor Loadings of the Model and between Factor Covariance on Clarity

\begin{tabular}{lllll}
\hline Item \# & B & SE B & $\boldsymbol{\beta}$ & \\
\hline$@ 11$ & 2.033 & 0.817 & 0.442 & Retained \\
$@ 22$ & 2.704 & 1.015 & 0.720 & Retained \\
$@ 23$ & 2.93 & 1.097 & 0.743 & Retained \\
$@ 25$ & 2.854 & 1.07 & 0.731 & Retained \\
$@ 27$ & 1.814 & 0.726 & 0.453 & Retained \\
\hline
\end{tabular}

Table 1 (e) Standardized and Unstandardized Factor Loadings of the Model and between Factor Covariance on Empathy

\begin{tabular}{lllll}
\hline Item \# & B & SE B & $\boldsymbol{\beta}$ & \\
\hline$@ 9$ & 1.283 & 0.253 & 0.498 & Retained \\
$@ 26$ & 1.091 & 0.215 & 0.497 & Retained \\
\hline
\end{tabular}


Table 2 Covariance and Correlation Between the Factors

\begin{tabular}{llllllll}
\hline $\mathbf{x}$ & & $\mathbf{y}$ & $\mathbf{c o v}(\mathbf{x}, \mathbf{y})$ & S.E. & $\mathbf{r}$ & $\mathbf{P}$ & sig. \\
\hline $\mathrm{SA}$ & $<-->$ & $\mathrm{Pr}$ & 0.025 & 0.019 & 0.55 & 0.18 & $\mathrm{~ns}$ \\
$\mathrm{SA}$ & $<-->$ & $\mathrm{Au}$ & 0.095 & 0.026 & $0.76^{* * *}$ & 0.00 & $\mathrm{~s}$ \\
$\mathrm{SA}$ & $<-->$ & $\mathrm{Cl}$ & 0.048 & 0.021 & $0.63^{*}$ & 0.02 & $\mathrm{~s}$ \\
$\mathrm{SA}$ & $<-->$ & $\mathrm{Em}$ & 0.116 & 0.03 & $0.94^{* * *}$ & 0.00 & $\mathrm{~s}$ \\
$\mathrm{Pr}$ & $<-->$ & $\mathrm{Au}$ & 0.032 & 0.024 & 0.74 & 0.18 & $\mathrm{~ns}$ \\
$\mathrm{Pr}$ & $<-->$ & $\mathrm{Cl}$ & 0.017 & 0.014 & 0.63 & 0.22 & $\mathrm{~ns}$ \\
$\mathrm{Pr}$ & $<-->$ & $\mathrm{Em}$ & 0.036 & 0.026 & 0.84 & 0.17 & $\mathrm{~ns}$ \\
$\mathrm{Au}$ & $<-->$ & $\mathrm{Cl}$ & 0.056 & 0.024 & $0.77^{*}$ & 0.02 & $\mathrm{~s}$ \\
$\mathrm{Au}$ & $<-->$ & $\mathrm{Em}$ & 0.136 & 0.034 & $1.17^{* * *}$ & 0.00 & $\mathrm{~s}$ \\
$\mathrm{Cl}$ & $<-->$ & $\mathrm{Em}$ & 0.067 & 0.028 & $0.93^{*}$ & 0.02 & $\mathrm{~s}$ \\
\hline
\end{tabular}

$* \mathrm{p}<.05 ; * * \mathrm{p}<.01 ; * * * \mathrm{p}<.001$

According to the analysis, it is found that the value of $\mathrm{P}$ is non-significant in the relationships between Situational Awareness and Presence $(\mathrm{P}=0.183)$, Presence and Authenticity $(\mathrm{P}=0.178)$, Presence and Clarity $(\mathrm{P}=0.219)$, and Presence and Empathy $(\mathrm{P}=0.175)$ indicating that they are measuring different aspects and also the tool's good reliability and validity. Whereas the value of $\mathrm{P}$ was found to be moderately significant in the relationships between Situational Awareness and Clarity $(\mathrm{P}=0.021)$, Authenticity and Clarity $(\mathrm{P}=0.019)$, and Clarity and Empathy $(\mathrm{P}=0.016)$ indicating that they might be measuring aspects that are slightly similar to each other.

Lastly, the value of $\mathrm{P}$ was found to be highly significant in the relationships between Situational Awareness and Authenticity, Situational Awareness and Empathy, and Authenticity and Empathy $(\mathrm{p}<0.01)$ indicating that they might be measuring the same aspect, this high correlation may have a negative effect on the tool's convergent validity and reliability.

Given the insignificant factor loading (insignificant relationship between the item and the latent factor it is supposed to measure) items \# 4, 6, 7, 8, 10, 12, 17, 24, 28, 29, 30, 32, and 33 are eliminated in the final model. 
Figure 5 The Final Five-correlated Factor Model of Social Intelligence

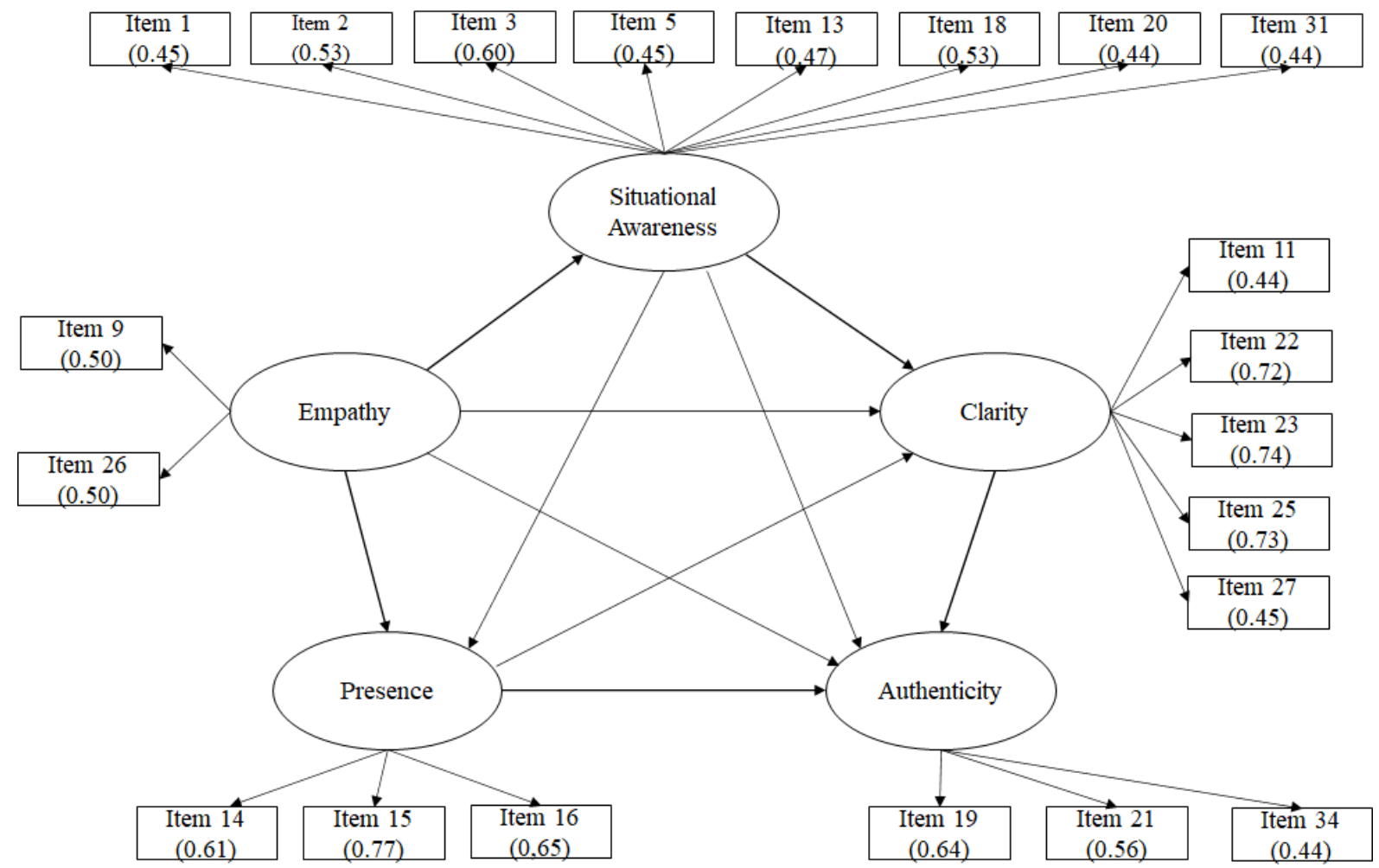

The items retained in the final model were found to have a good internal consistency $(\alpha=$ $0.87)$ in the sample. Factor wise internal consistency assessment indicated Situational Awareness had an $\alpha$ of 0.71 , Presence had an $\alpha$ of 0.72 , Authenticity had an $\alpha$ of 0.55 , Clarity had an $\alpha$ of 0.74, and Empathy had an $\alpha$ of 0.28. Except for empathy internal consistency has been reported to be found satisfactory. This indicates that a further revision of the items under the dimension of empathy or the addition of few more statements is required to ensure acceptable and strong internal consistency. However, the overall internal consistency of the newly developed tool has been found quite high and indicates that the tool can be used for the research purpose to investigate the psychological correlation of the construct in the Indian socio-cultural context.

Furthermore, the criterion validity of the tool was established by correlating the scores obtained on the tool with the scores obtained on Tromso Social Intelligence Scale (TSIS; Silvera, Martinussen, \& Dahl, 2001). The criterion validity was found to be good and significant $(r=0.164, p<.01)$. Obtained results for criterion validity ensure that the newly developed tool of social intelligence is assessing the construct very well but none of the statements overlaps with the existing scale for social intelligence i.e., TSIS.

\section{Descriptive Statistics:}

Based on the final structure of the developed tool to assess social intelligence, along with overall scores, scores on five dimensions including - Situational awareness (\#8 items), Presence (\#3 items), Authenticity (\# 3 items), Clarity (\# 5 items) and Empathy (\# 2 items). Hence for the present sample, descriptive statistics were run and the obtained values of mean and S.D. are presented as follows: 
Table 3 Summary for number of items, reliability, Likert scale, and min./max. possible score on the self-developed SIS and its dimensions $(N=182)$

\begin{tabular}{llllll}
\hline Dimension on SI & Items & $\boldsymbol{\alpha}$ & $\begin{array}{l}\text { Likert } \\
\text { Scale }\end{array}$ & Min. score & $\begin{array}{l}\text { Max. } \\
\text { Score }\end{array}$ \\
\hline Situational awareness & 8 & 0.71 & 1 to 5 & 8 & 40 \\
Presence & 3 & 0.72 & 1 to 5 & 3 & 15 \\
Authenticity & 3 & 0.55 & 1 to 5 & 3 & 15 \\
Clarity & 5 & 0.74 & 1 to 5 & 5 & 25 \\
Empathy & 2 & 0.28 & 1 to 5 & 2 & 10 \\
Overall SI & 21 & 0.87 & 1 to 5 & 21 & 105 \\
\hline
\end{tabular}

Table 4 Summary for descriptive statistics (Mean \& S.D.) and correlation on the selfdeveloped SIS and its dimensions $(N=182)$

\begin{tabular}{|c|c|c|c|c|c|c|c|c|c|}
\hline $\begin{array}{l}\text { Dimension } \\
\text { SI }\end{array}$ & on & (Abb.) & Mean & S.D. & $\mathbf{S A}$ & $\mathbf{P}$ & $\mathbf{A}$ & $\mathbf{C}$ & $\mathbf{E}$ \\
\hline $\begin{array}{l}\text { Situational } \\
\text { awareness }\end{array}$ & & SA & 31.03 & 3.67 & 1.00 & $0.52^{* *}$ & $0.42^{* *}$ & $0.50^{* *}$ & $0.52^{* *}$ \\
\hline Presence & & $\mathrm{P}$ & 11.43 & 2.16 & & 1.00 & $0.47^{* *}$ & $0.52^{* *}$ & $0.48^{* *}$ \\
\hline Authenticity & & A & 11.43 & 1.77 & & & 1.00 & $0.51^{* *}$ & $0.57^{* *}$ \\
\hline Clarity & & $\mathrm{C}$ & 19.76 & 3.00 & & & & 1.00 & $0.51^{* *}$ \\
\hline Empathy & & $\mathrm{E}$ & 8.08 & 1.24 & & & & & 1.00 \\
\hline
\end{tabular}

Figure 6 Plot of Mean Values of Dimensions on the Self-developed SIS

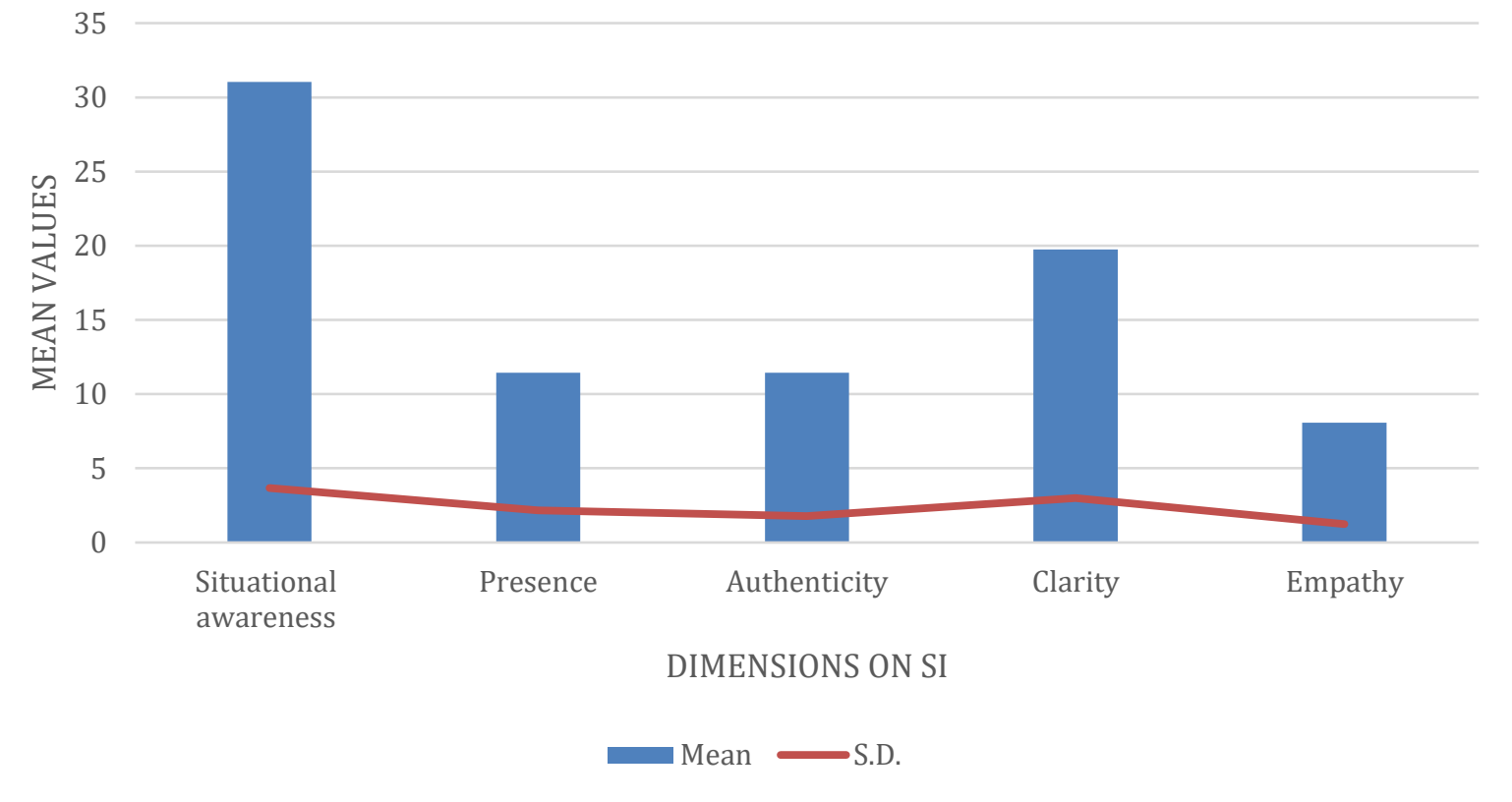

Dimension-wise mean scores obtained by participants were found to be $31.3,11.43,11.43$, 19.76, and 8.08 respectively for situational awareness (S.D.=3.67), presence (S.D.=2.16), authenticity (S.D.=1.77), clarity (S.D.=3.00), and empathy (S.D.=1.24). The overall mean score obtained by the participants in the tool was found to be 81.74 (S.D.=9.26). High mean scores both dimension-wise, as well as overall, indicate the prevalence of a higher level of 
social intelligence among the sample who took part in the study. This finding can be attributed to the locale distribution of the participants with $92.3 \%$ of them belonging either to urban or semi-urban locales, where people are said to have relatively better social exposure and awareness.

The intra-correlation among the dimensions of the tool was found to be ranging between 0.420.57 , which is considered as a moderate correlation. This indicates that there exists a relationship between the different dimensions of the tool. Further, that each dimension is measuring a different aspect of social intelligence and there is no overlap between the dimensions.

Table 5 Summary for descriptive statistics (Mean \& S.D.) and correlation on the selfdeveloped SIS and TSIS $(N=182)$

\begin{tabular}{lllll}
\hline Variables & Mean & S.D. & Overall SI & TSIS \\
\hline Overall SI & 81.74 & 9.26 & 1.00 & $0.16^{* *}$ \\
TSIS & 64.62 & 12.94 & & 1.00 \\
\hline
\end{tabular}

\section{Figure 7 Plot of Mean Values of Overall Score on the self-developed SIS and TSIS}

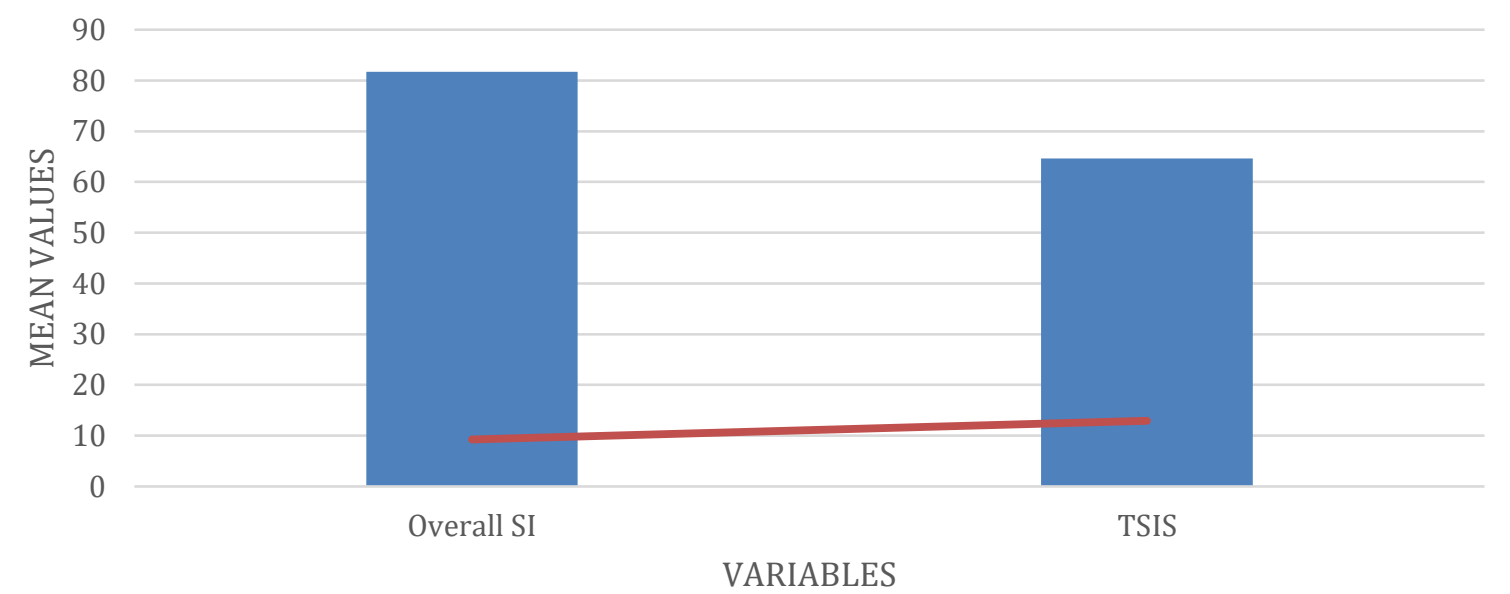

The overall mean score obtained by the participants was found to be 81.74 and 64.62 respectively on the self-developed SIS (S.D.=9.26) and TSIS (S.D.=12.94). The relatively higher mean score obtained by the participants on the SIS can be indicative of the tool's better applicability and appropriateness in the socio-cultural context of India when compared to TSIS, which was developed in a western country.

\section{CONCLUSIONS}

The aim of the study was to develop and validate a tool to measure the social intelligence quotient of employees at the workplace, especially during the time of recruitment. The tool was developed based on the five-part model of social intelligence developed by Karl Albrecht (2005). The sample considered in the study consisted of 222 individuals both male and female aged between 18 to 25, with an Indian origin. Structural Equation Modelling (SEM) was used to test the presence of five correlated factors of social intelligence. Five factors were extracted and were measured by different statements. Situational awareness (item \# 1, 2, 3, 5, 13, 18, 
20, \& 31), Presence (item \# 14, 15, \& 16), Authenticity (item \# 19, 21, \& 34), Clarity (item \# $11,22,23,25, \& 27$ ) and Empathy (item \# $9 \& 26$ ). The findings of the study indicate the tool to be a reliable and valid measure of social intelligence.

\section{Limitations}

- The model obtained is not satisfactorily fit which may be primarily attributed to the limited access to sample due to the pandemic and lockdown measures introduced to contain the same, which resulted in nullifying the possibility of offline data collection and may have also influenced the responses of people to some extent.

- The sample considered in the study belonged to the age group of 18-25 years therefore the model/structure obtained in this study cannot be normalized for all age groups.

- The gender distribution of the sample was highly skewed with almost three-fourth of the respondents being male $(73.8 \%)$.

- Lastly, despite social intelligence being a common trait this scale was developed to suit the Indian subcontinent therefore, the reliability and validity of the tool need to be established before being used in other countries, especially in western ones.

\section{Recommendations}

- This tool is recommended for new recruits but can also be used by organizations on existing employees to understand their level of social intelligence and accordingly provide the required training and support for employees who score relatively low.

- Employees can be assigned to different teams/departments based on their social intelligence which will aid the growth of the individual as well as the team. For example, in a product-based company, the importance attached to social intelligence is significantly different between an employee who works in the production department and the one who works in the marketing/customer service department.

- The tool can prove really useful while hiring for leadership roles or promoting existing employees to leadership positions. Aspects of social intelligence such as clear communication, being aware of the situation, and being empathetic to the concerns of team members are considered to be highly critical for a successful leader.

\section{Future Directions}

- More research needs to be undertaken to test and validate Karl Albrecht's five-part model of social intelligence.

- Focus group discussions have to be initiated to develop the statements which would be more appropriate in a socio-cultural context from the domain experts.

- Norms for the tool can be strengthened by developing it for different age groups, professions, and gender.

\section{REFERENCES}

Albrecht, K. (2005). Social Intelligence: The New Science of Success. Jossey-Bass.

Baggiyam, D., \& R, P. (2017). Social Intelligence in Relation to Academic Achievement. International Journal Of Research - Granthaalayah, 5(3), 18-22.

Barnes, M. L., \& Sternberg, R. J. (1989). Social intelligence and decoding of nonverbal cues. Intelligence, 13, 263-287.

Bar-On, R. (1997). The Bar-On Emotional Quotient Inventory (EQ-i): Technical Manual. Toronto: Multi-Health Systems.

Boyatzis, R., \& Goleman, D. (2017). Emotional and Social Competency Inventory-Research guide and technical manual. Korn Ferry. 
Boyatzis, R. (2018). The Behavioral Level of Emotional Intelligence and Its Measurement. Frontiers In Psychology, 9. https://doi.org/10.3389/fpsyg.2018.01438

Bänziger, T., Scherer, K., Hall, J., \& Rosenthal, R. (2011). Introducing the MiniPONS: A Short Multichannel Version of the Profile of Nonverbal Sensitivity (PONS). Journal of Nonverbal Behavior, 35(3), 189-204. https://doi.org/10.1007/s10919-011-0108-3

Cantor, N., \& Kihlstrom, J. F. (1987). Personality and social intelligence.Englewood Cliffs, New Jersey: Prentice Hall.

Cherniss, C., Extein, M., Goleman, D., \& Weissberg, R. P. (2006). Emotional intelligence: What does the research really indicate? Educational Psychologist, 41, 239-245.

Crowne, K. (2009). The relationships among social intelligence, emotional intelligence, and cultural intelligence. Organization Management Journal, 6(3), 148-163. https://doi.org/10.1057/omj.2009.20

Dogan, T. Cetin, B. (2009) The Validity, Reliability and Factorial Structure of the Turkish Version of the Tromso Social Intelligence Scale. (2009). Educational Sciences: Theory \& Practice, 9(2), 709-720.

Ebrahimpoor, H., Zahed, A., \& Elyasi, A. (2013). The Study of Relationship Between Social intelligence and Organizational Performance (Case Study: Ardabil Regional Water Company's Managers). International Journal of Organizational Leadership, 2(1), 110. https://doi.org/10.33844/ijol.2013.60352

Eysenck, H. J., \& Eysenck, S. B. (1963). Eysenck Personality Inventory. PsycTESTS Dataset. https://doi.org/10.1037/t02711-000

Frankovsky, M., \& Birknerova, Z. (2014). Measuring Social Intelligence-The MESI Methodology. Asian Social Science, 10(6). https://doi.org/10.5539/ass.v10n6p90

Friedman, S. Teacher emotional intelligence and the quality of their interactions with students. https://doi.org/10.7282/T3ZW1J16

Gardner, H. (1983). Frames of mind: The theory of multiple intelligence. Basic.

Gini, G. (2006). Brief report: Adaptation of the Italian version of the Tromso social intelligence scale to the adolescent population. Journal of Adolescence, 29, 307- 312.

Goleman, D. (1995). Emotional intelligence. Bantam Books.

Goswami, M. (2019). Assessing the Factor Structure of Tromso Social Intelligence Scale in Indian Cultural Context. SSRN Electronic Journal. https://doi.org/10.2139/ssrn.3446597

García-Bullé, S. (2020, July 31). What is social intelligence and why it should be taught at schools. Observatory of Educational Innovation. https://observatory.tec.mx/edunews/social-intelligence.

Gray, K., \& Gray, C. (2017). What is Structural Equation Modeling? KDnuggets. https://www.kdnuggets.com/2017/03/structural-equation-modeling.html.

Habib, S., Saleem, S., \& Mahmood, Z. (2013). Development and Validation of Social Intelligence Scale for University Students. Pakistan Journal of Psychological Research, 28(1), 65-83.

Kline, R. B. (1998). Principles and Practice of Structural Equation Modeling. The Guilford Press.

Lorincová, T., \& Lelková, A. (2016). Prediction of Manipulation, Empathy, and Social Irritability through Selected Personality Traits among Managers. Periodica Polytechnica Social And Management Sciences, 24(2), 83-87. https://doi.org/10.3311/ppso.8765

MacCallum, R. C., \& Austin, J. T. (2000). Applications of Structural Equation Modeling in Psychological Research. Annual Review of Psychology, 51(1), 201-226.

https://doi.org/10.1146/annurev.psych.51.1.201 
Mathias, J. (1988). Social intelligence and personal competence in mentally retarded adolescents (thesis).

O’Sullivan, M., Guilford, J. P., \& DeMille, R. (1965). The measurement of social intelligence. Psychological Laboratory Reports (Vol. 34). Los Angeles: University of Southern California.

Pagano, J., \& PaganoStudent, J. (2020, August 17). The Importance of Social Intelligence. The Positivity Project. https://posproject.org/the-importance-of-social-intelligence/.

Pinky. (2010). Emotional and social intelligence as predictors of happiness in adolescents (thesis).

Rosenthal, R., Hall, J.A., DiMatteo, M.R., Rogers, P.L., \& Archer, D. (2013). The Pons test manual (Revised). Northeastern University.

Rostamian, B., \& Sadrabadi, M. M. (2016). The Relation between Social Intelligent and Service Presentation Quality (Case Study: Selected Branches of Melat Bank of Isfahan City). Procedia - Social and Behavioral Sciences, 230, 290-297. https://doi.org/10.1016/j.sbspro.2016.09.037

Silvera, D., Martinussen, M., \& Dahl, T. (2001). The Troms $\varnothing$ Social Intelligence Scale, a selfreport measure of social intelligence. Scandinavian Journal Of Psychology, 42(4), 313-319. https://doi.org/10.1111/1467-9450.00242

Structural Equation Modeling. Statistics Solutions. (2020, December 4). https://www.statisticssolutions.com/structural-equation-modeling/.

Suhr, D. (2006). The Basics of Structural Equation Modeling. LexJansen. https://www.lexjansen.com/wuss/2006/tutorials/TUT-Suhr.pdf.

Thorndike, E. L. (1920). Intelligence and its use. Harper's Magazine, 140, 227-235.

Weis, S. (2008) Theory and Measurement of Social Intelligence as a Cognitive Performance Construct (Unpublished doctoral dissertation). Otto von Guericke University.

Wechsler, D. (1958). The measurement and appraisal of adult intelligence. (4th ed.). Williams \& Wilkins.

Wong, C. M. T., Day, J. D., Maxwell, S. E., Meera, N. M. (1995). A multitrait-multimethod study of academic and social intelligence in college students. Journal of Educational Research, 87, 117 - 133.

\section{Appendix}

\section{Karrthik Social Intelligence Inventory (KSII)}

Factor 1: Situational Awareness (S)

1. I can prioritize my tasks.

2. I can understand social situations.

3. I am aware of how things work.

4. I am good at comprehending social scenarios.

7. I can infer things which can't be observed directly.

11. Changes in the environment alerts me.

13. My acts are divergent across situations.

20. I am cautious to the changes around me.

Factor 2: Presence $(P)$

8. I can present myself at social gatherings.

9. I have a good social presence.

10 . I can project my personality consistently. 
Factor 3: Authenticity (A)

12. People perceive my actions as honest and ethical.

14. People view my actions as congruent to my values.

21. People perceive my values as influencing my behaviour

Factor 4: Clarity $(C)$

6 . I can give feedback directly and assertively.

15 . I can communicate clearly.

16. I can convey my ideas effectively.

17. I can provide valuable feedback.

19. I employ examples to convey my ideas effectively.

Factor 5: Empathy (E)

5. I can build valuable social relationships.

18. I empathize with people's feelings.

\section{Acknowledgement}

The author(s) appreciates all those who participated in the study and helped to facilitate the research process.

\section{Conflict of Interest}

The author(s) declared no conflict of interest.

How to cite this article: Ramanathan K. (2021). Development and Validation of a Tool on Social Intelligence. International Journal of Indian Psychology, 9(3), 1540-1560. DIP:18.01.143.20210903, DOI:10.25215/0903.143 